\title{
Spatiotemporal Analysis of the Effect of Ozone and Fine Particulate on CVD Emergency Room Visits in Harris County, Texas
}

\author{
Faye Anderson, Arch Carson, Lawrence Whitehead, Keith Burau \\ Texas A \& M AgriLIFE Research Center at Beaumont, Texas, USA \\ Email: Faye.Anderson@ag.tamu.edu
}

Received 12 October 2014; revised 12 November 2014; accepted 19 November 2014

Copyright (C) 2014 by authors and Scientific Research Publishing Inc.

This work is licensed under the Creative Commons Attribution International License (CC BY). http://creativecommons.org/licenses/by/4.0/

(c) (j) Open Access

\begin{abstract}
Researchers have reported statistically significant associations between air pollutants and cardiovascular disease (CVD). However, few studies have investigated the acute cardiovascular effects of joint exposure to Ozone (03) and fine particulate matter (PM2.5) in a location so distinctive like Harris County. The objective of this study was to investigate the association between the joint exposure to 03 and PM2.5, and emergency room diagnosis of CVD, in Harris County, Texas. Data used include all emergency room (ER) visits, and 03 and PM2.5 levels in the same years. Logistic regression modeled the effect of temperature, relative humidity, wind speed, wind, ozone, and fine particulate matter, averaged by day. Three models were estimated for all visits, visits during the months of April and September of 2005 and 2009, and for visits for patients from zip codes that are close to monitoring stations. A $1 \mu \mathrm{g} / \mathrm{m}^{3}$ increase in PM2.5 was associated with a $0.4 \%$ increase in the odds of cardiovascular disease emergency room diagnoses on the same day (p-value $<0.001$ ), and a $0.2 \%$ increase in the odds of cardiovascular disease emergency room diagnoses on the following day (p-value $<0.001$ ). This study demonstrated that there are statistically significant associations between ER visits for CVD diagnosis in Harris County, with joint exposure to 03 and PM2.5 of the same day and previous day. The increase of CVD cases as well as association between humidity and the numbers of CVD cases, males and blacks has higher odds.
\end{abstract}

\section{Keywords}

Cardiovascular Disease, Air Pollution, Emergency, Harris County, Ozone, Particulate Pollution

How to cite this paper: Anderson, F., Carson, A., Whitehead, L. and Burau, K. (2014) Spatiotemporal Analysis of the Effect of Ozone and Fine Particulate on CVD Emergency Room Visits in Harris County, Texas. Open Journal of Air Pollution, 3, 87-99. http://dx.doi.org/10.4236/ojap.2014.34009 


\section{Introduction}

Harris County is the third most populous county in the United States of America (US) hosting the second largest petrochemical complex in the world [1]. It also has a large and active outdoor air pollution monitoring system. Houston, which is largely coterminous with Harris County is the fourth most-populated city in the nation [2], suffers from high vehicular traffic emissions from the geographically extended eight-county Houston Galveston area and has a potential location that allows for domestic and international air pollution traffic [3]. Despite having a uniquely large network of air quality monitors (especially for ozone), during the six period of 2004 and 2009 Harris County has never been in long-term attainment for the NAAQS O3 standards [4]; it has been in attainment for PM2.5 standards since 2009 [5]. Hospitalization due to cardiovascular disease is correlated with exposure to O3 and PM2.5 (PM2.5) [6]. The average cost of an emergency room (ER) visit in Harris County for 2009 was four times that of national average (\$800 versus $\$ 200$, respectively) and the number of CVD ER visits for 2009 were highest than those for the previous five years. The ER visit rate of Harris County residents was about 32.84 per 1000 residents in 2009, exceeding the 30.91 and 30.0 ER visit rates in 2007 and 2008 respectively [7]. Houston; the county seat was one of the worst five cities in the U.S. regarding diesel PM health impacts on children in 1999 [8]. There is substantial evidence that fine particulate matter is associated with cardiovascular diseases in Houston despite its EPA attainment. In their study to investigate the effects of air pollutants in Houston, Sexton et al. (2005) stated that ozone and fine particulate matter are both carcinogens and systemic toxicants [9].

Harris County has characteristics that make it sufficiently dissimilar to other metropolitan areas to warrant specific study. These differences include: high ozone levels, a uniquely large network of air quality monitors (especially for ozone), mixed interactions between land-sea breeze air circulation, a large concentration of petrochemical industries, among the largest in the world, concentrated industrial emissions related to this industrial density in the Houston Ship Channel and Galveston Bay areas, large populations living among, and in the dispersion airshed from, the industrial areas, high vehicular traffic and corresponding emissions from the geographically extended urbanized eight-county Houston Galveston area, and potential pollution transport from domestic and international source regions [3], including additional petrochemical industry complexes ranging from Lake Charles, LA, and Beaumont-Orange, TX, to Freeport, TX, and south towards Corpus Christi.

The main question of this study was to investigate the association of CVD ER visits to joint exposure to PM2.5 and ozone, with daily lags of 0 and 1 day. Daily ER data for Harris County for the six years of 2004 through 2009 was linked to interpolated PM2.5 and O3 measurements. The dataset also contained temperature, relative humidity, wind direction, and wind speed. Adjusted and unadjusted maps were plotted for each outcome. Adjustment was made for race and gender. Three logistic regressions were performed: one for all records, another for visits during the four months of April and September of 2005 and 2009, and a third one for visits from zip codes that are close to PM2.5 monitoring stations (East of Harris County).

This is the first study to explore spatial and temporal trends over multiple years for Harris County, Texas. While majority of studies focus on either spatial or temporal association between exposure to O3 and/or PM2.5 and CVD ER visits, this study investigates the relationship both temporally and spatially. No similar study has ever been conducted for Harris County or for Houston. For example, in their recent study to model spatial patterns of adverse health effects of O3 in Houston, Lin and Lu (2009) study the effect of O3 levels in only four months on children with respiratory disease who needed hospital admission. The investigators come to the conclusion that due to lack of other confounders, their conclusions of spatial association could have been more precise. In their recommendations, they call for further investigations to study the effects over a longer period of time and on subjects of different ages. This study covers many of the missing pieces, for example including up to twenty sequential seasons (versus one), all ages, patients who did not need hospital admission, meteorological factors, and particulate pollution [10]. In their recent study, Raun et al. (2011) modeled 6812 calls to City of Houston 911 service that resulted in a diagnosis of out of hospital cardiac arrest, using time-stratified casecrossover model. Ozone temporal scale used was one hour, whereas particulate matter temporal scale used was one day. The effect of joint exposure to both pollutants was not investigated [11]. This study investigates ten diagnoses (versus one), with over 3.2 million emergency room visits (versus 6812) including visits by those who did not call 911, spatially distributed in 141 zip codes and over a temporal period of six years (versus four). Finally, their study did not investigate typical confounders like day of the week effect, and other non-summer seasonal effects.

In 2009, 1,127,557 ER visits were made to all twenty four participating hospitals. Of this total, 84.8\% were 
made by Harris County residents. The ER visits of participating hospitals are $74.04 \%$ of all ER visits reported to the Texas Department of State Health Services by all hospitals in Harris County in 2009 [7]. The large size of the database and hence the high statistical power of the analysis allows for the investigation of variances of exposure and the outcome (CVD). Furthermore, the data span of six years provides enough variance to study the daily, weekly, monthly and seasonal effects of exposure.

In their recent technical paper, Vizuete and Jeffries (2011), proficiently provide substantiation that O3 attainment methodology for Houston has technical issues like filtering the days with observed large hourly variability. This makes it miss the critical causes for high O3 concentrations [3]. This study's findings can support an improved O3 attainment methodology in Houston and the County.

\section{Methods}

\subsection{Data}

This study used data from three sources. The first dataset has Harris County daily emergency room visits for CVD from 2004 through 2009. This dataset was developed by Dr. Charles Begley (ER Utilization Study), UTSPH, under UT study number HSC-SPH-04-021. This includes ER visits for six years (1825 days) from hospitals that serve the general public of Harris County (provide hospital based ER care and accept 911 deliveries). The total number of ER visits included was 4,755,404. CVD emergency room visits are those with primary diagnosis of heart failure (ICD-9 code 428), heart rhythm disturbances (ICD-9 codes 426 - 427), cerebrovascular events (ICD-9 codes 430 - 438), ischemic heart disease (ICD-9 codes 410 - 414, 429), and peripheral vascular disease (ICD-9 codes 440 - 448) [12]. The second dataset is for O3 and PM2.5 for the same years (2004-2009), which contains hourly measurements for O3, PM2.5, temperature, relative humidity, wind speed and wind direction for each day of the six years, at a number of monitoring stations. The EPA analytical method code is "702-PM2.5 SCC w/Correction Factor, TEOM Gravimetric 50 deg C". These data are available to the public through the Texas Commission on Environmental Quality TCEQ website for the Texas Air Monitoring Information System (TAMIS). To investigate possible confounding effect by meteorological factors, wind speed and wind direction was included. Wind direction is a circular variable. Thus to overcome the issue of inconsistency in variable types, wind direction was reduced into its sine and cosine components before using in the proposed generalized model. The sine wind component points towards the east (wind blows from west to east) and was referred to as west-east wind component, and the cosine wind component points towards the north (wind blows from south to north) and was referred to as south-north wind component. The third dataset is publically available as well. It contains the centroid coordinates for Harris County zip codes from Texas State Data Center website. STATA v13, Golden Surfer 9 and MapInfov10 were used to conduct regressions, interpolation and mapping respectively.

\subsection{Spatiotemporal Analyses}

While ER visit data has the zip code of the patient's address, O3 and PM2.5 measurements are not available for each zip code. Therefore, O3 and PM2.5 levels between monitoring sites were spatially interpolated using kriging. Daily averages of the two pollutants were interpolated using kriging for the different zip-code regions of the County. This statistically estimated levels of the pollutants in locations without monitors in each day of the six years (2004 to 2009). For PM2.5, the daily readings from the eight monitors were used to produce contour maps for every day in every zip region of the County. This was done in the case of O3 using the nineteen monitors available. The years 2004 to 2009 have 2192 days. Kriging created 4384 (2192 times 2 pollutants) datasets, which contained estimates of the levels of both O3 and PM2.5 for every ER visit in every day of the six years of 2004 to 2009 (linked by date and zip area centroid). Exposure levels (by date and zip area centroid) were matched to each ER visit.

\subsection{Logistic Regression}

Logistic regression was performed one with the binary outcome of the ER visit being of CVD primary diagnosis. Bivariate models were performed prior to multiple logistic regression. Odds ratios (ORs) of CVD outcome, Wald Maximum Likelihood (WML) statistics, 95\% confidence intervals, and p-values were calculated. Crude (unadjusted, bivariate logistic regression) and adjusted (multivariate logistic regression) modeling will be per- 
formed. Adjusted logistic model were controlled for age, gender and race. Although, the total number of records is estimated to be $4,755,404$, the number of records used for analysis was fewer since only residents of Harris County were included. The predictors used were O3, PM2.5, age, temperature, relative humidity, wind speed, west-east wind component, and south-north wind component. The choice of the regression best suits the nature of the outcomes and predictors-logistic regression measures the association between dichotomous dependent variable (CVD) and the independent variables. The logistic model assumes that the logit of the probability for CVD ER visits is a linear function of the independent variables including O3 and PM2.5. The logit of a probability $\mathrm{p}$ is defined as $\log (\mathrm{p} / 1-\mathrm{p})$. The logistic prediction equation used was: $\operatorname{logit}[\mathrm{P}(\mathrm{CVD}$ diagnosis $=1)]=$ intercept $+\mathrm{B} 1 *$ temperature $+\mathrm{B} 2 *$ relative humidity $+\mathrm{B} 3 *$ west-east wind $+\mathrm{B} 4 *$ south-north wind $+\mathrm{B} 5$ * wind speed $+\mathrm{B} 6 *$ age $+\mathrm{B} 7 *$ race $+\mathrm{B} 8 *$ sex $+\mathrm{B} 9 *$ day of the week $+\mathrm{B} 10 * \mathrm{PM} 25+\mathrm{B} 11 * \mathrm{O} 3+\mathrm{B} 12 *$ O3lag $1+$ B13* PM25lag 1 .

\subsection{Cross Validation}

To assess the quality of our model and validate the findings and conclusions drawn from modeling the data, split-sample validation was performed. In this validation approach, the ER visits are randomly divided into two subsets: A training sample containing $80 \%$ of the ER visits and a holdout sample containing the remaining $20 \%$ of the ER visits were used. The training sample was used to develop the logistic regression model. The holdout sample was grouped using the coefficients based on the training sample. The grouping accuracy for the holdout sample is used to estimate how robust the model based on the training sample is for the population represented by the ER dataset used. If the grouping accuracy rate of the holdout sample is within ten percent of the training sample, it was sufficient evidence of the effectiveness of the logistic regression model. In addition to satisfying the grouping accuracy, it was required that the significance, at alpha $=0.05$, of the overall relationship and the relationships with individual predictors for the training sample match the significance results for the model using the full data set [13].

\section{Results and Discussion}

Bivariate analysis unadjusted odds ratios found that age ( $\mathrm{OR}=1.059,95 \% \mathrm{CI}=1.059-1.060, \mathrm{p}<0.001)$, being male $(\mathrm{OR}=1.250,95 \% \mathrm{CI}=1.235-1.267, \mathrm{p}<0.001)$, relative humidity $(\mathrm{OR}=1.001,95 \% \mathrm{CI}=1.000-1.001$, $\mathrm{p}=0.001)$, west-east wind component $(\mathrm{OR}=1.004,95 \% \mathrm{CI}=1.002-1.007, \mathrm{p}<0.001)$, south-north wind component $(\mathrm{OR}=1.002,95 \% \mathrm{CI}=1.001-1.004, \mathrm{p}<0.001)$, $\mathrm{PM} 2.5$ of the same day $(\mathrm{OR}=1.003,95 \% \mathrm{CI}=1.002-$ 1.005, $\mathrm{p}<0.001)$, and PM2.5 of the previous day (OR $=1.003,95 \% \mathrm{CI}=1.002-1.005, \mathrm{p}<0.001)$ were associated with CVD ER visit diagnosis (Table 1). In the logistic regression model, there is a significant association of emergency room CVD diagnosis in Harris County, Texas, with exposure to PM2.5 of lag 0 (OR $=1.004,95 \%$ $\mathrm{CI}=1.002-1.005, \mathrm{p}<0.001)$ and $1(\mathrm{OR}=1.002,95 \% \mathrm{CI}=1.001-1.004, \mathrm{p}<0.001)$ days, adjusting for race, gender, day of the week, relative humidity, temperature, west-east wind component, south-north wind component, wind speed (Table 2). The ratios of training set odds ratios to holdout set odds ratios for CVD ER visit diagnosis model adjusted adjusting for race, gender, day of the week, relative humidity, temperature, west-east wind component, south-north wind component, wind speed range from 1.21 to 2.83 percent (0.0121 to 0.0283 ).

Contour maps for monthly means of O3 and PM2.5 are presented in Figure 1 and Figure 2 respectively. For ozone, higher concentrations were on the outer boundary of the County. Overall, April concentrations were higher than those of September for the two years (Figure 1). For PM2.5, September of 2005 monthly mean was the highest of the four months. In April 2005, PM2.5 monthly concentration was lower in the eastern parts of the County. In April 2009, it was lower at the outer boundary of the County. In September 2009, monthly concentration of PM2.5 was mostly between 10 and $12 \mu \mathrm{g} / \mathrm{m}^{3}$ (Figure 2).

For CVD monthly incidence proportion mean, the southwest zip code regions between I610 and BW8 had higher incidence proportions than the rest for April 2005, September 2009, and April 2005. April and September of 2009 monthly incidence proportion means were also higher from zip code regions around highway US59 and Beltway 8 (Figure 3). Bivariate analysis unadjusted odds ratios found that age (OR $=1.05,95 \% \mathrm{CI}=1.058$ 1.061, $\mathrm{p}<0.001)$, being male ( $\mathrm{OR}=1.22,95 \% \mathrm{CI}=1.15-1.29, \mathrm{p}<0.001)$, and $\mathrm{O} 3$ of the same day $(\mathrm{OR}=1.00$, $95 \% \mathrm{CI}=1.001-1.007, \mathrm{p}=0.002)$ were associated with CVD ER visit diagnosis during the months of April and September of 2005 and 2009 (Table 3). In the logistic regression model, there is a significant association of emergency room CVD diagnosis in Harris County, Texas during the months of April and September of 2005 


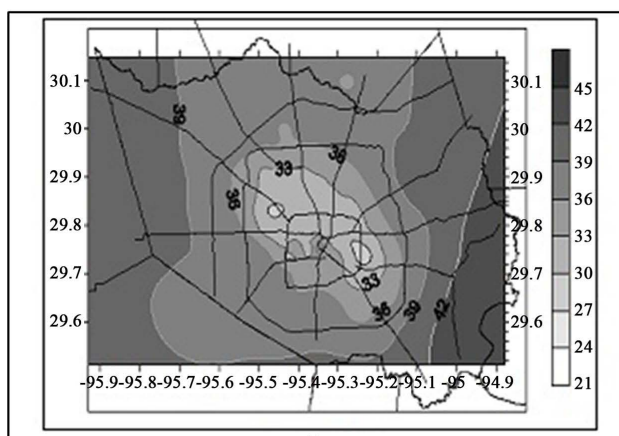

April 2005

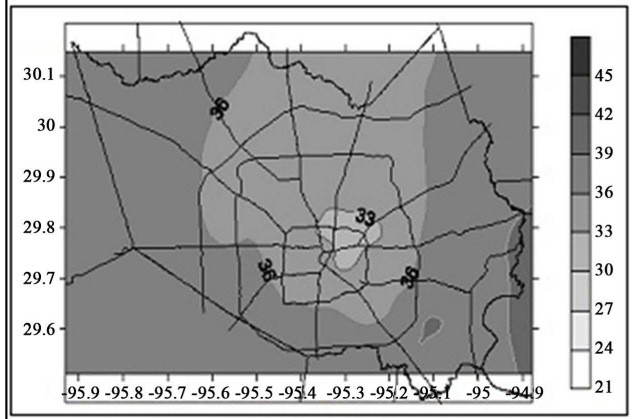

April 2009

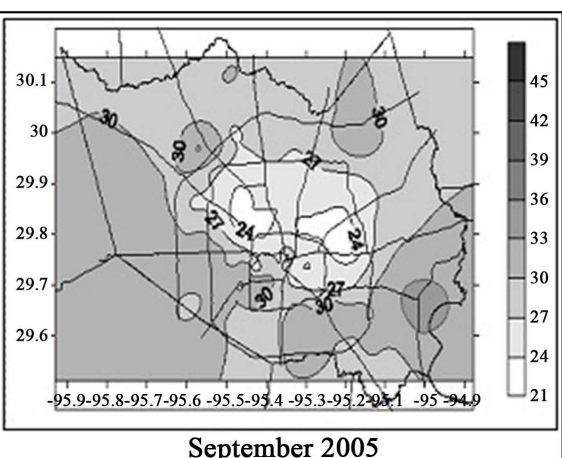

September 2005

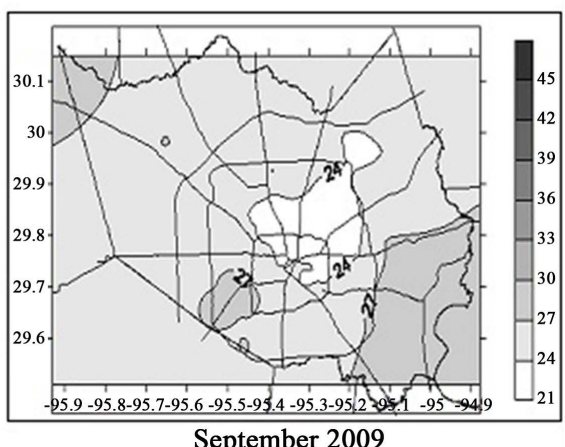

September 2009

Figure 1. Ozone monthly mean contour maps (ppb) for Apr. 2005, Sep. 2005. Apr. 2009 and Sep. 2009 using Ordinary Kriging.

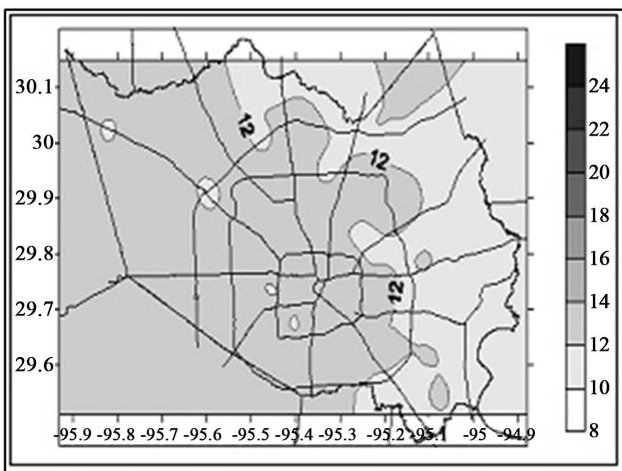

April 2005

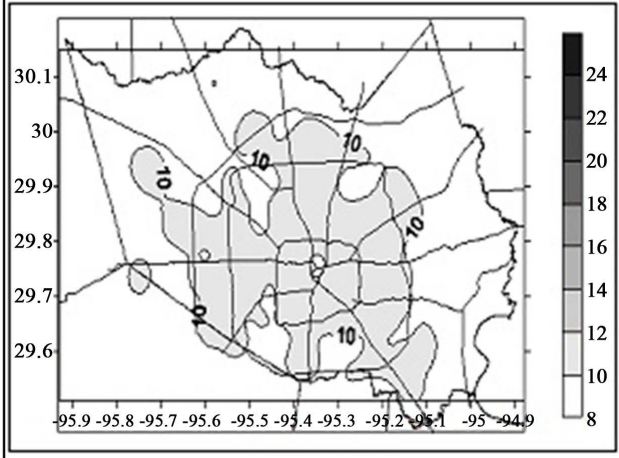

April 2009

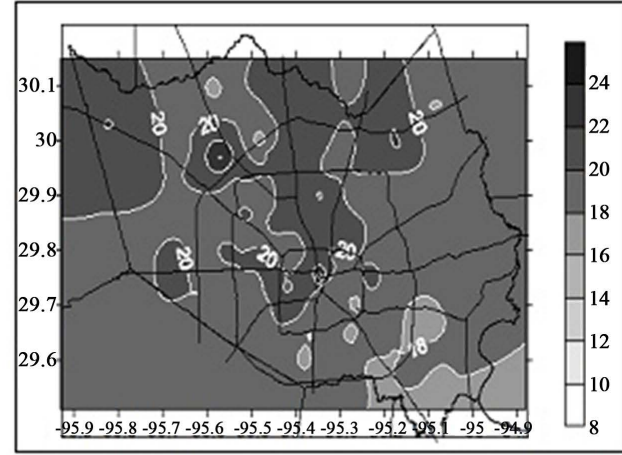

September 2005

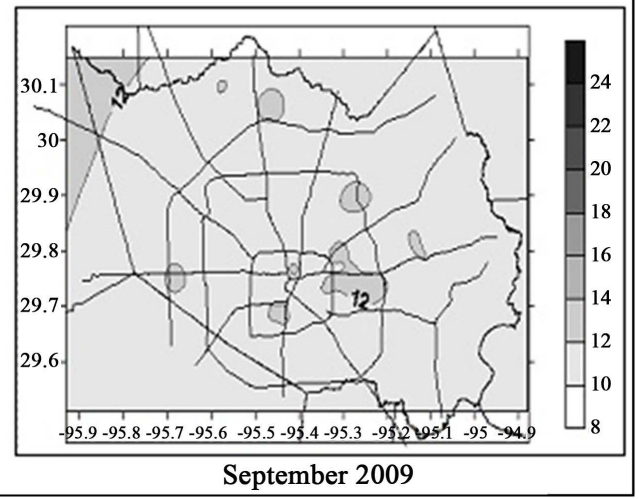

September 2009

Figure 2. PM2.5 monthly mean contour maps $\left(\mu \mathrm{g} / \mathrm{m}^{3}\right)$ for Apr. 2005, Sep. 2005. Apr. 2009 and Sep. 2009 using Ordinary Kriging. 


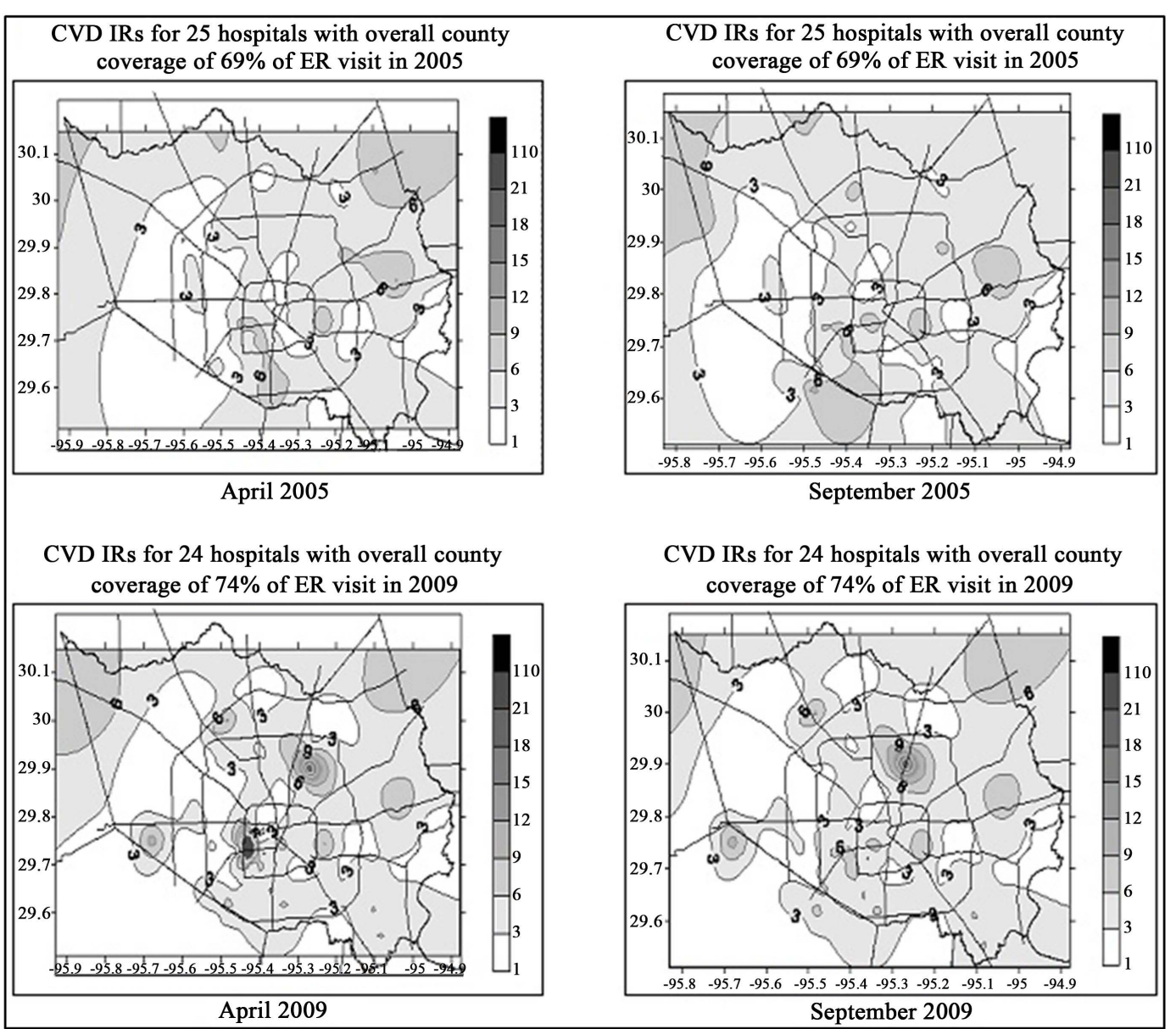

Figure 3. CVD monthly average incidence rate contour maps for Apr. 2005, Sep. 2005, Apr. 2009 and Sep. 2009 using Ordinary Kriging.

Table 1. Estimated unadjusted odds ratio of CVD ER visit diagnosis by risk factors.

\begin{tabular}{|c|c|c|c|c|c|}
\hline Variable $(\mathrm{N}=3,252,102)$ & Mean (SD) & OR & $\mathrm{p}$ value & \multicolumn{2}{|c|}{$95 \%$ CI } \\
\hline Day of the week (ref = Monday) & $15 \%$ & 1.000 & & & \\
\hline Tuesday & $14 \%$ & 0.989 & 0.350 & 0.9666087 & 1.012114 \\
\hline Wednesday & $14 \%$ & 0.981 & 0.114 & 0.9589807 & 1.004508 \\
\hline Thursday & $14 \%$ & 0.991 & 0.477 & 0.9687997 & 1.014944 \\
\hline Friday & $14 \%$ & 0.975 & 0.034 & 0.9525589 & 0.9981089 \\
\hline Saturday & $14 \%$ & 0.845 & $<0.001$ & 0.8256781 & 0.8662819 \\
\hline Sunday & $15 \%$ & 0.830 & $<0.001$ & 0.8109016 & 0.8506679 \\
\hline Race (ref = White) & $28 \%$ & 1.000 & & & \\
\hline Hispanic & $34 \%$ & 0.303 & $<0.001$ & 0.2983889 & 0.3092735 \\
\hline Black & $32 \%$ & 0.565 & $<0.001$ & 0.5573505 & 0.5743619 \\
\hline Other & $6 \%$ & 0.542 & $<0.001$ & 0.5280698 & 0.558187 \\
\hline Gender (ref = Female) & $56 \%$ & 1.000 & & & \\
\hline
\end{tabular}




\section{Continued}

$\begin{array}{cccccc}\text { Male } & 44 \% & 1.250 & <0.001 & 1.235508 & 1.267562 \\ \text { Age (years) } & 31.98(23.88) & 1.059 & <0.001 & 1.059156 & 1.059816 \\ \text { Relative humidity (\%) } & 70.70(11.79) & 1.001 & 0.001 & 1.000379 & 1.001468 \\ \text { Temperature (Deg Fahrenheit) } & 70.34(11.97) & 0.997 & <0.001 & 0.9973328 & 0.9983927 \\ \text { West-east wind component (KPH East) } & 1.09(2.54) & 1.004 & <0.001 & 1.002237 & 1.007309 \\ \text { South-north wind component (KPH North) } & -1.34(4.05) & 1.002 & <0.001 & 1.001314 & 1.004484 \\ \text { Wind speed (KPH) } & 4.54(2.28 & 0.988 & <0.001 & 0.9857598 & 0.9913376 \\ \text { Ozone (ppb) } & 24.28(9.77) & 0.996 & <0.001 & 0.9961274 & 0.9974428 \\ \text { Ozone lag } 1(\mathrm{ppb}) & 24.31(9.77) & 0.997 & <0.001 & 0.9967367 & 0.9980507 \\ \text { PM2.5 }\left(\mu \mathrm{g} / \mathrm{m}^{3}\right) & 11.86(4.96) & 1.003 & <0.001 & 1.002237 & 1.004798 \\ \text { PM2.5 lag } 1\left(\mu \mathrm{g} / \mathrm{m}^{3}\right) & 11.86(4.96) & 1.003 & <0.001 & 1.002211 & 1.004772\end{array}$

Table 2. Estimated odds ratio of CVD ER visit diagnosis adjusted by risk factors.

\begin{tabular}{|c|c|c|c|c|c|}
\hline Variable $(\mathrm{N}=3,252,102)$ & Mean (SD) & OR & $\mathrm{p}$ value & \multicolumn{2}{|c|}{$95 \%$ CI } \\
\hline & (1) & & & & \\
\hline Tuesday & $14 \%$ & 0.987 & 0.297 & 0.9637226 & 1.01136 \\
\hline Wednesday & $14 \%$ & 0.981 & 0.129 & 0.9577559 & 1.005526 \\
\hline Thursday & $14 \%$ & 0.984 & 0.206 & 0.9606604 & 1.008703 \\
\hline Friday & $14 \%$ & 0.928 & $<0.001$ & 0.9057085 & 0.9511435 \\
\hline Saturday & $14 \%$ & 0.853 & $<0.001$ & 0.8318118 & 0.8747339 \\
\hline Sunday & $15 \%$ & 0.886 & $<0.001$ & 0.8644382 & 0.9089482 \\
\hline Race (ref = White) & $28 \%$ & 1.000 & & & \\
\hline Hispanic & $34 \%$ & 0.778 & $<0.001$ & 0.7637261 & 0.7934626 \\
\hline Black & $32 \%$ & 1.074 & $<0.001$ & 1.057249 & 1.092004 \\
\hline Other & $6 \%$ & 0.942 & $<0.001$ & 0.9156536 & 0.9704968 \\
\hline Gender (ref = Female) & $56 \%$ & 1.000 & & & \\
\hline Male & $44 \%$ & 1.604 & $<0.001$ & 1.582828 & 1.626146 \\
\hline Age (years) & 31.98 (23.88) & 1.059 & $<0.001$ & 1.059616 & 1.060315 \\
\hline Relative humidity (\%) & 70.70 (11.79) & 1.001 & $<0.001$ & 1.000992 & 1.002345 \\
\hline Temperature (Deg Fahrenheit) & $70.34(11.97)$ & 0.996 & $<0.001$ & 0.9954985 & 0.9969112 \\
\hline West-east wind component (KPH East) & $1.09(2.54)$ & 1.006 & $<0.001$ & 1.003794 & 1.009734 \\
\hline South-north wind component (KPH North) & $-1.34(4.05)$ & 0.999 & 0.843 & 0.9975699 & 1.00199 \\
\hline Wind speed (KPH) & $4.54(2.28$ & 0.988 & $<0.001$ & 0.985361 & 0.9920663 \\
\hline Ozone (ppb) & 24.28 (9.77) & 0.999 & 0.346 & 0.9988183 & 1.000415 \\
\hline Ozone lag 1 (ppb) & $24.31(9.77)$ & 0.998 & $<0.001$ & 0.9978347 & 0.9992475 \\
\hline PM2.5 $\left(\mu \mathrm{g} / \mathrm{m}^{3}\right)$ & $11.86(4.96)$ & 1.004 & $<0.001$ & 1.002528 & 1.005566 \\
\hline PM2.5 lag $1\left(\mu \mathrm{g} / \mathrm{m}^{3}\right)$ & $11.86(4.96)$ & 1.002 & $<0.001$ & 1.001276 & 1.00403 \\
\hline
\end{tabular}


Table 3. Estimated unadjusted odds ratio of CVD ER visit diagnosis by risk factors (Apr. 2005, Sep. 2005. Apr. 2009, Sep. 2009).

\begin{tabular}{|c|c|c|c|c|c|}
\hline Variable $(\mathrm{N}=197,496)$ & Mean (SD) & OR & $\mathrm{p}$ value & \multicolumn{2}{|c|}{$95 \%$ CI } \\
\hline & & & & & \\
\hline Thursday & $14 \%$ & 0.937 & 0.199 & 0.848891 & 1.034672 \\
\hline Friday & $13 \%$ & 0.938 & 0.219 & 0.8485279 & 1.038318 \\
\hline Saturday & $14 \%$ & 0.851 & 0.002 & 0.767907 & 0.9440128 \\
\hline Sunday & $13 \%$ & 0.785 & $<0.001$ & 0.7066834 & 0.87307 \\
\hline Monday & $14 \%$ & 0.926 & 0.133 & 0.8393631 & 1.023409 \\
\hline Tuesday & $15 \%$ & 0.871 & 0.007 & 0.7887894 & 0.9622248 \\
\hline Race (ref = White) & $28 \%$ & 1.000 & & & \\
\hline Hispanic & $35 \%$ & 0.287 & $<0.001$ & 0.2655958 & 0.310311 \\
\hline Black & $31 \%$ & 0.548 & $<0.001$ & 0.5134043 & 0.5858827 \\
\hline Other & $6 \%$ & 0.521 & $<0.001$ & 0.4595165 & 0.5921362 \\
\hline Gender (ref = Female) & $56 \%$ & 1.000 & & & \\
\hline Male & $45 \%$ & 1.225 & $<0.001$ & 1.158763 & 1.296112 \\
\hline Age (years) & 31.45 (23.84) & 1.059 & $<0.001$ & 1.058421 & 1.061276 \\
\hline Relative humidity (\%) & 70.46 (11.24) & 0.999 & 0.827 & 0.9972402 & 1.002212 \\
\hline Temperature (Deg Fahrenheit) & $74.26(6.71)$ & 0.991 & $<0.001$ & 0.9877039 & 0.9958479 \\
\hline West-east wind component (KPH East) & $0.88(3.27)$ & 0.995 & 0.358 & 0.9875231 & 1.004546 \\
\hline South-north wind component (KPH North) & $-0.82(4.01)$ & 1.002 & 0.429 & 0.9958419 & 1.009855 \\
\hline Wind speed (KPH) & $4.69(2.49)$ & 0.996 & 0.497 & 0.9849954 & 1.007365 \\
\hline Ozone (ppb) & $30.75(9.86)$ & 1.004 & 0.002 & 1.001636 & 1.007356 \\
\hline Ozone lag 1 (ppb) & $25.77(10.25)$ & 0.996 & 0.005 & 0.9933481 & 0.9988286 \\
\hline PM2.5 $\left(\mu \mathrm{g} / \mathrm{m}^{3}\right)$ & $11.97(5.26)$ & 0.984 & $<0.001$ & 0.978768 & 0.9899128 \\
\hline PM2.5 lag $1\left(\mu \mathrm{g} / \mathrm{m}^{3}\right)$ & $11.78(4.85)$ & 0.988 & $<0.001$ & 0.9822433 & 0.9940469 \\
\hline
\end{tabular}

and 2009, with exposure to ozone of lag $0(\mathrm{OR}=1.01,95 \% \mathrm{CI}=1.01-1.02, \mathrm{p}<0.001)$, adjusting for race, gender, day of the week, relative humidity, temperature, west-east wind component, south-north wind component, wind speed (Table 4).

To test the hypothesis more accurately, the ER visits from zip code regions surrounding PM2.5 monitoring stations were analyzed (East Harris County). Bivariate analysis unadjusted odds ratios found that age, being male, relative humidity, west-east wind, and south-north wind component were associated with CVD ER visit diagnosis during the months of April and September of 2005 and 2009 (Table 5). In the logistic regression model, the hypothesis cannot be accepted for ER visits during April and September of 2005 and 2009 (Table 6).

In summary, ozone concentration of the same day has a significant association with CVD cases of the data of April/September 2005 and 2009 analysis. Ozone of previous day has a significant association with cases during April/September 2005 and 2009 analysis. Additionally, ozone and PM2.5 are also associated with CVD cases from the combined case of all records. PM2.5 of previous day is associated with CVD cases from the combined case of all records. The last comparison is the association of PM2.5 to the outcome of CVD. In the combined case of all records versus the data from zip code regions (east) close to PM2.5 monitoring stations, this indicates that the number and location of the current monitoring stations seems to be reasonable enough to detect statistically significant association between the health outcomes and PM2.5. 
Table 4. Estimated odds ratio of CVD ER visit diagnosis adjusted by risk factors (Apr. 2005, Sep. 2005. Apr. 2009, Sep. 2009).

\begin{tabular}{|c|c|c|c|c|c|}
\hline Variable $(\mathrm{N}=197,496)$ & Mean (SD) & OR & $\mathrm{p}$ value & \multicolumn{2}{|c|}{$95 \% \mathrm{CI}$} \\
\hline Thursday & $14 \%$ & 0.911 & 0.091 & 0.8181136 & 1.01495 \\
\hline Friday & $13 \%$ & 0.885 & 0.042 & 0.7877297 & 0.9954976 \\
\hline Saturday & $14 \%$ & 0.840 & 0.003 & 0.7483287 & 0.9433443 \\
\hline Sunday & $13 \%$ & 0.779 & $<0.001$ & 0.6966273 & 0.8720196 \\
\hline Monday & $14 \%$ & 0.912 & 0.086 & 0.8224617 & 1.01316 \\
\hline Tuesday & $15 \%$ & 0.861 & 0.006 & 0.7756397 & 0.9576237 \\
\hline Race (ref = White) & $28 \%$ & 1.000 & & & \\
\hline Hispanic & $35 \%$ & 0.775 & $<0.001$ & 0.7136899 & 0.8423265 \\
\hline Black & $31 \%$ & 1.095 & 0.011 & 1.020836 & 1.176471 \\
\hline Other & $6 \%$ & 0.889 & 0.082 & 0.778618 & 1.015184 \\
\hline Gender (ref = Female) & $56 \%$ & 1.000 & & & \\
\hline Male & $45 \%$ & 1.591 & $<0.001$ & 1.499957 & 1.687341 \\
\hline Age (years) & 31.45 (23.84) & 1.060 & $<0.001$ & 1.058713 & 1.061747 \\
\hline Relative humidity (\%) & $70.46(11.24)$ & 1.009 & $<0.001$ & 1.005166 & 1.014364 \\
\hline Temperature (Deg Fahrenheit) & $74.26(6.71)$ & 1.001 & 0.662 & 0.9941536 & 1.00927 \\
\hline West-east wind component (KPH East) & $0.88(3.27)$ & 0.993 & 0.278 & 0.9824304 & 1.005104 \\
\hline South-north wind component (KPH North) & $-0.82(4.01)$ & 1.000 & 0.946 & 0.990568 & 1.010204 \\
\hline Wind speed (KPH) & $4.69(2.49)$ & 0.962 & $<0.001$ & 0.947403 & 0.9775057 \\
\hline Ozone (ppb) & $30.75(9.86)$ & 1.015 & $<0.001$ & 1.011025 & 1.020929 \\
\hline Ozone lag 1 (ppb) & $25.77(10.25)$ & 1.001 & 0.580 & 0.9978774 & 1.003802 \\
\hline $\operatorname{PM} 2.5\left(\mu \mathrm{g} / \mathrm{m}^{3}\right)$ & $11.97(5.26)$ & 0.975 & $<0.001$ & 0.9662081 & 0.9839788 \\
\hline PM2.5 lag $1\left(\mu \mathrm{g} / \mathrm{m}^{3}\right)$ & $11.78(4.85)$ & 0.993 & 0.034 & 0.9867124 & 0.9994737 \\
\hline
\end{tabular}

Table 5. Estimated unadjusted odds ratio of CVD ER visit diagnosis by risk factors—East Harris County.

\begin{tabular}{ccccccc}
\hline Variable $(\mathrm{N}=478,580)$ & Mean $(\mathrm{SD})$ & OR & p value & \multicolumn{2}{c}{$95 \% \mathrm{CI}$} \\
\hline Day of the week (ref = Monday) & $15 \%$ & 1.000 & & & \\
Tuesday & $15 \%$ & 0.992 & 0.814 & 0.9358943 & 1.053427 \\
Wednesday & $14 \%$ & 0.959 & 0.181 & 0.9036419 & 1.0193 \\
Thursday & $14 \%$ & 1.005 & 0.859 & 0.9470626 & 1.067386 \\
Friday & $14 \%$ & 0.997 & 0.935 & 0.9394726 & 1.059156 \\
Saturday & $14 \%$ & 0.886 & $<0.001$ & 0.8340603 & 0.9425436 \\
Sunday & $14 \%$ & 0.847 & $<0.001$ & 0.7973294 & 0.9017739 \\
Race (ref = White) & $27 \%$ & 1.000 & & & & 0.3601379 \\
Hispanic & $47 \%$ & 0.345 & $<0.001$ & 0.3321632 & 0.7738604 \\
Black & $22 \%$ & 0.742 & $<0.001$ & 0.7129954 & 0.796 \\
\hline
\end{tabular}




\section{Continued}

\begin{tabular}{cccccc}
\hline Other & $4 \%$ & 0.514 & $<0.001$ & 0.4706722 & 0.5614462 \\
Gender (ref = Female) & $56 \%$ & 1.000 & & & \\
Male & $45 \%$ & 1.222 & $<0.001$ & 1.180879 & 1.261245 \\
Age (years) & $1.62(24.20)$ & 1.061 & $<0.001$ & 1.060163 & 1.061913 \\
Relative humidity (\%) & $70.81(11.84)$ & 1.002 & 0.002 & 1.000759 & 1.003556 \\
Temperature (Deg Fahrenheit) & $70.38(11.96)$ & 0.997 & $<0.001$ & 0.9956502 & 0.9983664 \\
West-east wind component (KPH East) & $1.09(2.54)$ & 1.011 & 0.001 & 1.004522 & 1.017673 \\
South-north wind component $(\mathrm{KPH}$ North) & $-1.36(4.05)$ & 1.007 & $<0.001$ & 1.003476 & 1.011631 \\
Wind speed $(\mathrm{KPH})$ & $4.55(2.89)$ & 0.984 & $<0.001$ & 0.9777402 & 0.991994 \\
Ozone $(\mathrm{ppb})$ & $23.48(9.47)$ & 0.998 & 0.051 & 0.9965253 & 1.000008 \\
Ozone lag $1(\mathrm{ppb})$ & $23.60(9.50)$ & 1.000 & 0.813 & 0.9984786 & 1.001942 \\
PM2.5 $\left(\mu \mathrm{g} / \mathrm{m}^{3}\right)$ & $11.97(5.05)$ & 1.002 & 0.211 & 0.9988298 & 1.005323 \\
PM2.5 lag $1\left(\mu \mathrm{g} / \mathrm{m}^{3}\right)$ & $11.93(5.02)$ & 1.003 & 0.056 & 0.9999179 & 1.006435 \\
\hline
\end{tabular}

Table 6. Estimated odds ratio of CVD ER visit diagnosis adjusted by risk factors-East Harris County.

\begin{tabular}{|c|c|c|c|c|c|}
\hline Variable $(\mathrm{N}=478,580)$ & Mean (SD) & OR & $\mathrm{p}$ value & \multicolumn{2}{|c|}{$95 \%$ CI } \\
\hline Tuesday & $15 \%$ & 0.985 & 0.642 & 0.9259542 & 1.048546 \\
\hline Wednesday & $14 \%$ & 0.962 & 0.234 & 0.9032969 & 1.025181 \\
\hline Thursday & $14 \%$ & 0.995 & 0.897 & 0.9351843 & 1.060455 \\
\hline Friday & $14 \%$ & 0.945 & 0.081 & 0.8877402 & 1.006887 \\
\hline Saturday & $14 \%$ & 0.895 & 0.001 & 0.8397726 & 0.9550761 \\
\hline Sunday & $14 \%$ & 0.904 & 0.002 & 0.8478122 & 0.9650165 \\
\hline Race (ref = White) & $27 \%$ & 1.000 & & & \\
\hline Hispanic & $47 \%$ & 0.793 & 0.001 & 0.7594512 & .8282103 \\
\hline Black & $22 \%$ & 1.047 & 0.036 & 1.003073 & 1.094351 \\
\hline Other & $4 \%$ & 0.878 & 0.006 & 0.8007882 & 0.9632332 \\
\hline Gender (ref = Female) & $56 \%$ & 1.000 & & & \\
\hline Male & $45 \%$ & 1.567 & $<0.001$ & 1.513783 & 1.622786 \\
\hline Age (years) & $31.62(24.20)$ & 1.061 & $<0.001$ & 1.060208 & 1.062031 \\
\hline Relative humidity (\%) & $70.81(11.84)$ & 1.003 & $<0.001$ & 1.001734 & 1.005229 \\
\hline Temperature (Deg Fahrenheit) & $70.38(11.96)$ & 0.996 & $<0.001$ & 0.994607 & 0.9982408 \\
\hline West-east wind component (KPH East) & $1.09(2.54)$ & 1.012 & 0.001 & 1.004832 & 1.020447 \\
\hline South-north wind component (KPH North) & $-1.36(4.05)$ & 1.005 & 0.067 & 0.9996313 & 1.01105 \\
\hline Wind speed (KPH) & 4.55 (2.89) & 0.984 & 0.001 & 0.9763909 & 0.9936054 \\
\hline Ozone (ppb) & $23.48(9.47)$ & 1.000 & 0.576 & 0.998472 & 1.002756 \\
\hline Ozone lag 1 (ppb) & $23.60(9.50)$ & 1.000 & 0.830 & 0.9983444 & 1.002067 \\
\hline PM2.5 $\left(\mu \mathrm{g} / \mathrm{m}^{3}\right)$ & $11.97(5.05)$ & 1.002 & 0.218 & 0.9985806 & 1.006259 \\
\hline PM2.5 lag $1\left(\mu \mathrm{g} / \mathrm{m}^{3}\right)$ & $11.93(5.02)$ & 1.003 & 0.102 & 0.9994239 & 1.00644 \\
\hline
\end{tabular}


Incidence proportion of CVD cases following Hurricane Rita (Thursday 9/22/2005 to Sunday 9/25/2055) are very similar to the same diagnoses averaged over the six year period; incidence proportions where higher for visits happening during the weekend. The results of the adjusted logistic model for CVD cases show that the odds for blacks were $7 \%$ higher than the odds for whites, and the odds for males were $60 \%$ higher than females. Moreover, the odds increase by increasing age, relative humidity, east wind, PM2.5 concentration of the same day and the day before. CVD may be influenced by race, ethnicity, gender and genetic inheritances. Limited data exists that compares CVD in different racial or ethnic groups. However this data suggests that differences may exist. Potential differences between racial or ethnic groups may include biological differences as well as disparities in diagnosis and treatment. It may also include lack of enrollment of minorities in epidemiological trials. Gender appears to also influence CVD. Historically, men have had higher prevalence rates of CVD than women, but recent data suggests that women may actually be more susceptible to CVD. CVD in women may have different characteristics than in men, and it may be more severe. More importantly, in the United States, more women now die of CVD than men. These results are consistent with other studies conducted in the United States [14] [15]. Although more women than men die of heart disease each year, women get fewer CVD diagnoses by their primary care physicians and emergency room staff [16] This may help explain the higher odds for [14] [15].

The higher odds for CVD cases with increasing age can be explained by the natural physiologic changes that occur with old age, one of which is lowered heart effectiveness and efficiency. Normal changes in the heart in old age include heart muscle cells degenerating slightly and the valves inside the heart, which control the direction of blood flow, thicken and become stiffer. This all contributes to the elderly being more prone to cardiovascular disease [17]. The higher odds of CVD cases with higher relative humidity and east wind can be explained by the exacerbation role that these variables play. The two variables play a significant role in how much ozone is transported to and from Harris County [18]. These findings were also observed in highly humid areas in the United Kingdom [19].

The logistic models used were robust because the ratios of training set odds ratios to holdout set odds ratios were small. The training set contained $80 \%$ of the ER visits and a holdout sample contained the remaining $20 \%$.

Incidence proportions for CVD cases increased from 2004 to 2009 by a factor of nine. This is a serious epidemiological finding especially when compared to national prevalence of the outcome for the same years. There are many plausible explanations for this many-fold increase in CVD ER visits diagnoses during the six years. Including but not limited to socioeconomic reasons. According to data released by the United States Census Bureau on June 14, 2006, Houston's Harris County received 92,824 immigrants as a result of Hurricane Rita and Hurricane Katrina, immediately prior to and following the hurricanes. However, higher estimates of immigrates have settled in Harris County, approximately one million during 18 month period following the hurricanes. Most of them were African Americans who did not have jobs, or lost their homes because of the hurricanes [20]. This (economic status) makes their choice to seek medical care at ERs expected.

The results of the adjusted logistic model for CVD cases for the four month period April/September 2005 and 2009 are consistent with these modeled for the six years. The third and final analysis involved ER visits from the zip codes near PM2.5 monitoring stations (East of Harris County). It showed that CVD incidence proportion remained almost the same during the six year period 2004-2009. The results of the adjusted logistic model for CVD cases for this special case (East Harris County) show that the odds for blacks were $5 \%$ higher than the odds for whites, and the odds for males were $57 \%$ higher than females. Additionally, the odds increased as age increased, as relative humidity increased, and as the east wind increased. However the odds for CVD did not increase or decrease with concentrations of ozone or PM2.5.

The role of wind in the models can be interpreted by the effect of wind on the formation of the two pollutants, ozone and PM2.5. Its role in forming ozone in Harris County can be summarized by the following; Houston's weather and location is perfect for the formation of ozone. Ozone is formed on warm, sunny days with little to no wind and no rain. But the sea breeze coming from the Gulf of Mexico, to the south and southeast, also helps to move the ozone polluted air around the Houston region. The predominant winds come from the southeast carrying pollution from the Houston Ship Channel (where a large concentration of nitrogen oxides and volatile organic compounds have been measured) and pushes these pollutants out to the northwest [21].

\section{Limitations}

Daily concentrations for PM2.5 and O3 were obtained kriging as a proxy for individual exposure. The kriged 
daily measurements will not be as accurate as personal exposure levels. Further, the zip code centroid associated with home address will be utilized for determining the most likely site of exposure. For zip codes where the modeled PM2.5 and O3 exposures are variable within the zip code, this will increase the error variability within the sample and will potentially lead to reduced ability to measure an associated health effect. Another limitation is the possible existence of bias from misclassifying primary diagnoses due to data entry or other errors. Moreover, the dataset did not contain possible confounders like smoking and life style. Another limitation is the use of daily average concentration rather than peak concentrations or moving window concentrations. These other ways of looking at the data may be useful, based upon the hypothesis.

\section{Conclusion}

The dataset included all ER visit data for hospitals participating in the Emergency Room Utilization Study 2004 to 2009. There were 96,596 CVD cases during this six-year period. After adjustment for age, race, gender, day of the week, temperature, relative humidity, west-east and south-north components of wind direction, and wind speed, there were statistically significant associations between an emergency room visit for cardiovascular disease diagnosis and exposure to PM2.5 of same day and previous day. Despite the small association between the two air pollutants and the health outcome, this study points to important findings. Namely, the continuing increase of CVD cases in Harris County, the significant association between increasing humidity and the numbers of CVD cases, and blacks and males has significantly increased odds compared to other ethnicities and females respectively. Moreover, this research suggests that the number and distribution of PM2.5 monitors in Harris County-although not even, are adequate to permit detection of significant associations between exposure and the two outcomes. Finally, this study points to other potential factors that contribute to the rising incidence proportions of CVD in Harris County such as patient history, life style, and other pollutants.

\section{Acknowledgements}

Special thanks go to Dr. Charles Begley for providing the data, and to Patrick Courtney for his technical support.

\section{References}

[1] Port of Houston Authority (PHA) (2011) Clean Air Strategy Plan, Environmental Affairs Department. http://www.portofhouston.com/pdf/environmental/CASP.\%202011 .pdf

[2] United States Census Bureau (US Census) (2014) Harris County, Texas. http://quickfacts.census.gov/qfd/states/48/48201.html

[3] Vizuete, W. and Jeffries, H. (2011) Issues with Ozone Attainment Methodology for Houston, TX. Journal of the Air \& Waste Management Association, 61, 238-253. http://dx.doi.org/10.3155/1047-3289.61.3.238

[4] Texas Commission on Environmental Quality (TCEQ) (2011) Attainment Status. http://www.tceq.texas.gov/airquality/sip/hgb/hgb-status

[5] United States Environmental Protection Agency (EPA) (2010) PM2.5 Attainment. http://www.epa.gov/pmdesignations/2006standards/final/region6.htm

[6] Roy, A., Sheffield, P., Wong, K. and Trasande, L. (2011) The Effects of Outdoor Air Pollutants on the Costs of Pediatric Asthma Hospitalizations in the United States, 1999 to 2007. Medical Care, 49, 810-817. http://dx.doi.org/10.1097/MLR.0b013e31820fbd9b

[7] Begley, C., Courtney, P. and Burau, K. (2011) Houston Hospitals Emergency Department Use Study. http://www.sph.uth.tmc.edu/uploadedFiles/Redesign_Website/Research/Research_Centers/Center_for_Health_Service s_Research/HSRC/Final2009BegleyMonday.pdf

[8] Hill, L. (2005) An Analysis of Diesel Air Pollution and Public Health in America. http://www.catf.us/resources/whitepapers/files/Diesel_in_America_Technical_Paper.pdf

[9] Sexton, K., Linder, S., Delclos, G., Stock, T., Abramson, S., Bondy, M., et al. (2005) A Closer Look at Air Pollution in Houston: Identifying Priority Health Risks. http://www.epa.gov/ttn/chief/conference/ei16/session6/bethel.pdf

[10] Lin, S. and Lu, Y. (2009) The Spatial Patterns of Adverse Health Effects of Ozone Pollution on Childhood Respiratory Diseases in Urban Houston. Annals of GIS, 15, 127-140. http://dx.doi.org/10.1080/19475680903271133

[11] Raun, L., Ensor, K. and Persse, D. (2011) Out of Hospital Cardiac Arrest Based on the Levels of Ozone and Fine Particulates. http://www.trackinginaction.com/pdfs/science/4/Raun.pdf 
[12] Rosamond, W., Flegal, K., Friday, G., Furie, K., et al. (2007) American Heart Association Statistical Update. http://sociedades.cardiol.br/socerj/area-cientifica/Heart_Disease_and_Stroke_Statistics_2007.pdf

[13] Athanasiou, T. and Darzi, A. (2009) Key Topics in Surgical Research and Methodology. Springer, Heidelberg.

[14] Centers for Disease Control and Prevention (CDC) (2012) Eliminate Disparities in Cardiovascular Disease (CVD). http://www.cdc.gov/omhd/amh/factsheets/cardio.htm

[15] Mensah, G. and Brown, D. (2007) An Overview Of Cardiovascular Disease Burden in the United States. http://content.healthaffairs.org/content/26/1/38.full

[16] Coulter, S. (2011) Women at High Risk. http://texasheart.org/AboutUs/News/feb08heartmonth.cfm

[17] Cabin, H. and Henry, S. (1992) The Heart and Circulation. In: Barry, L., Zaret, M.D., Marvin Moser, M.D., Lawrence, S. and Cohen, M.D., Eds., Yale University School of Medicine Heart Book, William Morrow \& Co., New York, 3-10.

[18] Jammalamadaka, S. and Lund, U. (2006) The Effect of Wind Direction on Ozone Levels: A Case Study. Environmental and Ecological Statistics, 13, 287-298. http://dx.doi.org/10.1007/s10651-004-0012-7

[19] Price, G. (2007) Effects of Weather, Air Quality and Geographical Location on Asthma and COPD Exacerbations in the Localities of Worcester and Dudley. http://eprints.worc.ac.uk/360/

[20] Koerber, K. (2006) Migration Patterns and Mover Characteristics from the 2005 ACS Gulf Coast Area Special Products. http://www.census.gov/newsroom/emergencies/additional/gulf_migration.html

[21] Air Alliance Houston (AAH) (2012) Air Pollution 101. http://airalliancehouston.org/content/air-pollution-101 
Scientific Research Publishing (SCIRP) is one of the largest Open Access journal publishers. It is currently publishing more than 200 open access, online, peer-reviewed journals covering a wide range of academic disciplines. SCIRP serves the worldwide academic communities and contributes to the progress and application of science with its publication.

Other selected journals from SCIRP are listed as below. Submit your manuscript to us via either submit@scirp.org or Online Submission Portal.
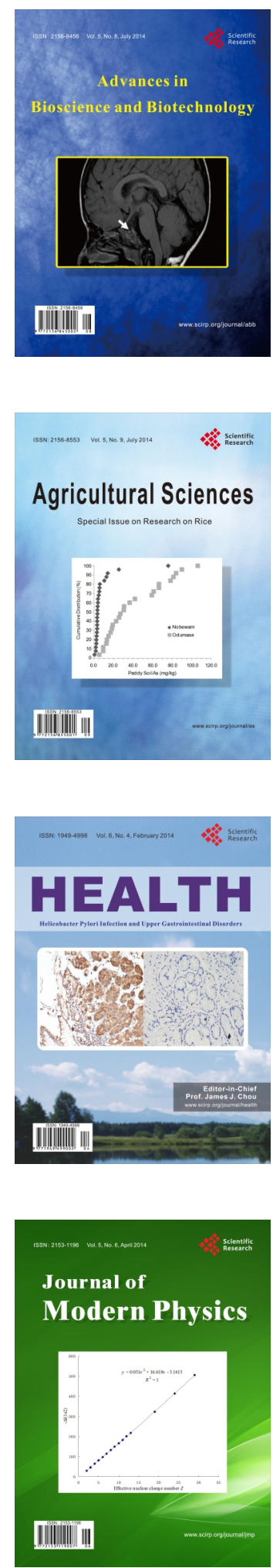
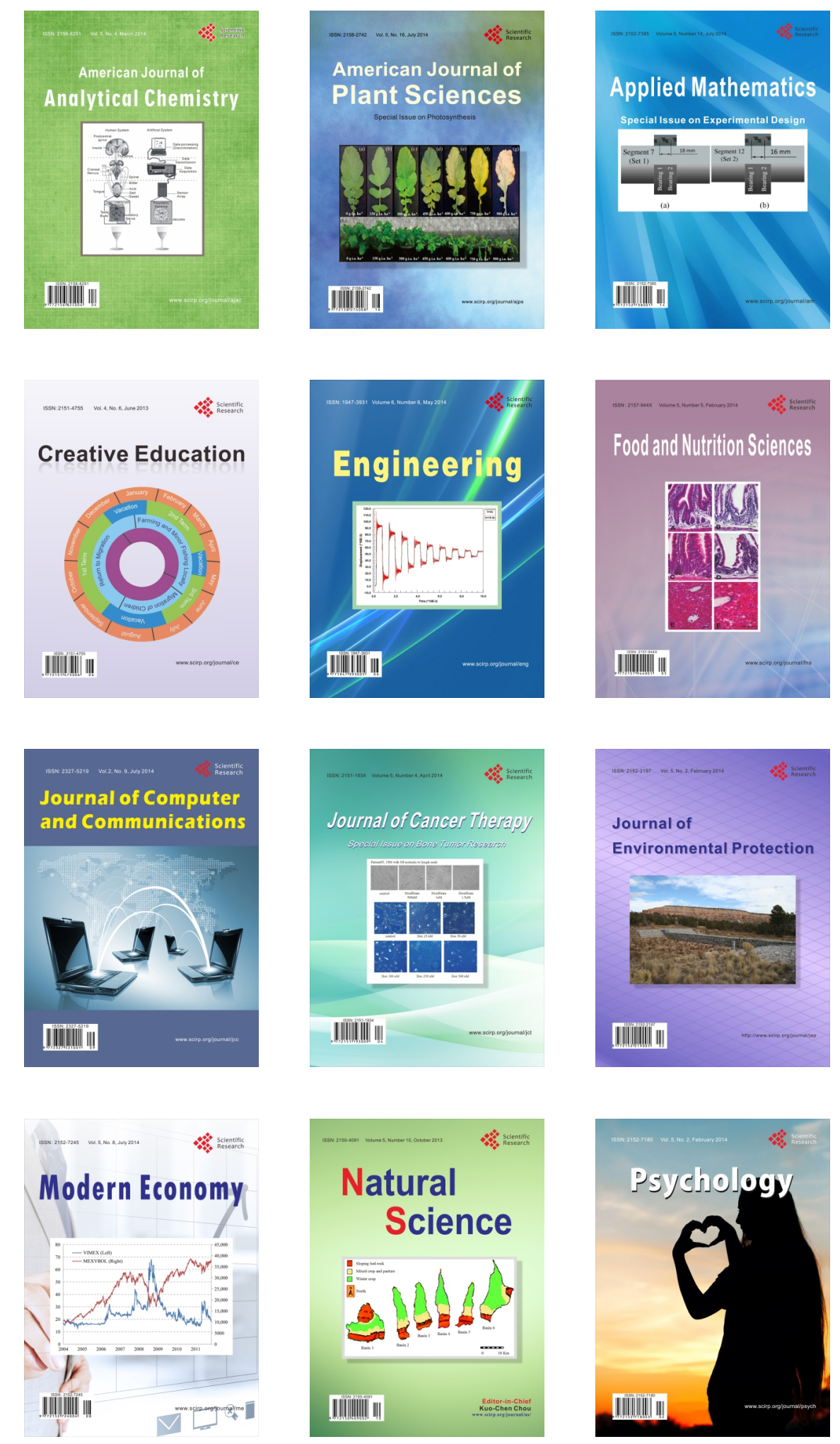